\title{
Os diários de Franz Kafka: uma introdução ${ }^{1}$
}

\author{
[The diaries of Franz Kafka: an introduction] \\ http://dx.doi.org/10.11606/1982-88372545187
}

\author{
Sâmella Freitas Russo ${ }^{2}$
}

\begin{abstract}
For fourteen years, Franz Kafka kept twelve quarto-size notebooks, in which he recorded his peculiar existence. Known as his personal diaries, these notebooks serve as a valuable source for understanding not only his life but also - and especially - his literary legacy. Nevertheless, little attention is still given by critics and academia to these texts as an exclusive object of investigation, sometimes due to the constraints exerted by the remnants of poststructuralist approaches, sometimes due to the peculiarities of their reception and translation. This article aims to present an overview of those twelve notebooks, discussing their origin, reception, translation, particularities, structure and content. As the criticism in Brazil concerning both the diary genre and Kafka's notebooks is scarce, this introduction can help potential readers and researchers interested in these diaries to contextualize them and consequently to facilitate the development of more advanced research about these notes.
\end{abstract}

Keywords: Franz Kafka; diaries; translation; reception; particularities.

Resumo: Franz Kafka manteve doze cadernos in-quarto ao longo de quatorze anos e fez neles o registro da sua peculiar existência. Conhecidos como seus diários íntimos, esses cadernos servem de valiosa fonte para a compreensão não apenas da vida do escritor como também - e especialmente - do seu legado literário. Não obstante, pouca atenção ainda é dada pela crítica e pela academia a esses textos como objeto exclusivo de investigação, ora pelo constrangimento exercido pelos resquícios das abordagens pós-estruturalistas, ora pela recepção e pela tradução a que se sujeitaram. Este artigo tem o propósito de apresentar um panorama desses doze cadernos, abrangendo sua origem, sua recepção, sua tradução, suas particularidades, sua estrutura e seu conteúdo. Por ser a crítica em nosso país tanto a respeito do gênero diário quanto dos cadernos in-quarto de Kafka escassa, essa apresentação pode auxiliar potenciais leitores e interessados nesses diários a contextualizá-los e consequentemente permitir o desenvolvimento de pesquisas mais aprofundadas acerca dessas notas.

Palavras-chave: Franz Kafka; diários; tradução; recepção; particularidades.

\section{Os diários: um panorama}

Conhecido como um dos maiores expoentes da literatura em língua alemã, Franz Kafka foi, antes de tudo, um exímio diarista. Para além de toda a escrita ficcional, deixou em

\footnotetext{
${ }^{1}$ Este artigo objetiva divulgar parte de pesquisa de tese de doutorado defendida em 2020.

${ }^{2}$ Universidade de São Paulo, Departamento de Letras Modernas, Av. Professor Luciano Gualberto, 403, Cidade Universitária, São Paulo/SP, 05.508-010, Brasil. E-mails: samellarusso@gmail.com; samellarusso@alumni.usp.br. ORCID: 0000-0002-4603-341X
}

\section{(cc) BY-NC}

Pandaemonium, São Paulo, v. 25, n. 45, jan.-abr. 2022, p. 187-211 
RUSSO, S. - Os diários de Franz Kafka: uma introdução

meio ao seu legado papéis de caráter essencialmente pessoal, dentre os quais milhares de cartas, postais, cadernetas de reflexões filosóficas (cadernos in-oitavo) e doze surpreendentes cadernos em formato in-quarto [Quarthefte] que ficaram conhecidos como os seus diários íntimos. Muito se conjecturou - e se conjectura - acerca do autor e da obra, mas sua escrita íntima permanece pouco difundida mesmo junto de seus leitores mais interessados. É amparado principalmente nisso que o presente artigo se dedica às notas dispersas nesses doze cadernos - assim como nos dois maços de papéis avulsos [Konvolut] que somam 9 páginas e também integram esses diários -, ainda hoje bastante relegados entre nós.

Kafka tinha vinte e seis anos quando inaugurou o primeiro caderno de capa preta envernizada com cerca de $25 \mathrm{~cm}$ de altura e $20 \mathrm{~cm}$ de largura, no qual deu início à manifestação da sua peculiar subjetividade - os cadernos compartilham as mesmas características físicas e são, em sua maioria, na cor marrom, com exceção dos dois primeiros, na cor preta (T1: 33 ss.). Mantidos por quatorze anos (1909-1923), ${ }^{3}$ neles escreveu usualmente com caneta de tinta preta - só raramente usou caneta azul ou lápis -, e as suas entradas pessoais são separadas sempre por um traço horizontal. Tendo em vista o formato desses cadernos, é provável que todos eles fossem compostos por cerca de 60 folhas não pautadas. Habituado o diarista a arrancar folhas desses cadernos para finalidades diversas, esse número, porém, varia bastante quando do acesso aos manuscritos: o primeiro dentre eles é o mais completo dos doze, com 58 das prováveis 60 páginas, e os mais incompletos são os últimos, especialmente o $9^{\circ}$ e o $10^{\circ}$ cadernos, com cerca de 1/3 das folhas originais (T1: 18-21).

Pouco se sabe efetivamente sobre a origem desses cadernos, mas é pertinente mencionar alguns aspectos que se encontram difundidos na - e pela - crítica voltada a esses diários, em especial a mais antiga. Curiosa é a alegação de Max Brod (1966: 110), o amigo a quem coube a tarefa de reunir todos os escritos de Kafka após a sua morte e supostamente destruí-los, de que ele teria sido o responsável por eles, quando afirma que o presenteou com a primeira caderneta que mais tarde daria origem à sua prática diarística em uma viagem de férias empreendida por ambos no outono de 1909. Por muitas décadas, pensou-se, devido a essa afirmação e à "negligência" de Kafka no apontamento das datas, que os diários teriam surgido no ano de 1910, uma vez que a primeira data indicada

\footnotetext{
${ }^{3}$ Paralelamente aos primeiros diários foram mantidos também diários de viagem (1911-1913), que não são, todavia, foco deste artigo.
}

Pandaemonium, São Paulo, v. 25, n. 45, jan.-abr. 2022, p. 187-211 
RUSSO, S. - Os diários de Franz Kafka: uma introdução

aparece apenas na $15^{\mathrm{a}}$ entrada e refere-se ao mês de maio daquele ano (mai.1910). Foi tão somente nos anos 1990 que essa impropriedade foi reparada, quando Hans-Gerd Koch, Michael Müller e Malcolm Pasley, responsáveis pela edição crítica dos papéis de Kafka e baseados nas datas em que os eventos mencionados pelo diarista se deram em Praga, esclareceram que os diários teriam tido início já no ano anterior, na primavera de 1909 (T2: 11, BINDER 1979: 539). Com essa correção temporal, fica evidente que ao menos duas estações - primavera e verão - afastam a hipótese de Brod acerca da origem desses cadernos. Há ainda estudiosos que advogam pela existência de diários anteriores a 1909 que teriam sido provavelmente destruídos, como Hartmut Binder (1976: 42 ss. e 1979: 539) e Peter-André Alt (2005: 160), mas fato é que, não obstante a possibilidade de aventar tais hipóteses, não há nenhum indício palpável que comprove a existência seja de diários anteriores a 1909, seja de posteriores a 1923.

Acerca do número de diários, um comentário é ainda pertinente: a crítica mais antiga fala não de doze, senão de treze diários. Este é um equívoco que teve origem quando da entrega dos cadernos à Milena Jesenská pelo próprio diarista em out.1921 - e que será abordada mais adiante. Não tendo completado o último diário, Kafka teria arrancado as doze primeiras folhas do $12^{\circ}$ caderno e entregado à Milena como parte do conjunto de sua escrita diarística, e o caderno passou a ser utilizado de trás para frente nas folhas restantes. Anos mais tarde, quando Brod levou esses textos a público, esses registros mais tardios foram apresentados como parte de um suposto $13^{\circ}$ caderno, que acabou sendo devidamente incluído no $12^{\circ}$ pela edição crítica (T1: 48 e 109, BROD 1962: 598, BINDER 1979: 548).

Os doze cadernos possuem certas particularidades que tornam a prática do diarista bastante singular. Uma marca das entradas feitas neles consiste em um anacronismo temporal em razão da já mencionada negligência de Kafka no apontamento das datas e que, por sua vez, pode provocar algumas confusões. Pouco criterioso na indicação do tempo nos registros e para além dos equívocos em relação às datas e das omissões, a demarcação temporal sequer é sequencial, aspecto que fica especialmente evidente após a edição crítica. Essa não-sequencialidade decorre principalmente do fato de ele ter usado distintos cadernos alternadamente, e o anacronismo advindo disso acarreta uma dificuldade adicional sobre a qual vale a pena um esclarecimento: comentadores e estudiosos dos diários (THEISOHN 2010: 378, T3: 85, ROTHER 2007: 37) usualmente afirmam que alguns deles foram utilizados simultaneamente, ou seja, ao mesmo tempo, a 
RUSSO, S. - Os diários de Franz Kafka: uma introdução

exemplo do $1^{\circ}$ e $2^{\circ}$ cadernos, o que é um equívoco. Kafka iniciou o $1^{\circ}$ caderno e nele fez anotações até 19.jun.1910, data em que foi deixado de lado. Passados 4 meses, em nov.1910, ele retomou a atividade, mas em um novo caderno, o $2^{\circ}$. Este, por sua vez, foi usado de nov.1910 a mar.1911, época em que retomou o $1^{\circ}$. Há, de fato, uma nota no $2^{\circ}$ após a retomada do $1^{\circ}$ (26.mar.1911), mas esse único registro não parece suficiente para caracterizar um revezamento entre eles - algo muito semelhante acontece nos $7^{\circ}, 8^{\circ}$ e $9^{\circ}$ diários.

Esse anacronismo tem como consequência uma controvérsia acerca da prática mantida: a hipótese de que, em razão do não apontamento da data nas primeiras páginas tanto do primeiro quanto do segundo cadernos in-quarto, Kafka não teria a intenção de escrever propriamente um diário. De fato, entre a nota inaugural até o aparecimento da primeira data (mai.1910), a prática foi episódica e, mesmo após o apontamento, não constante, cenário que se altera tão somente em agosto de 1911, quando ela passa a ter alguma regularidade. De todo modo, deve-se atentar para o fato de que foi o próprio Kafka a avaliar essas notas e batizá-las como "diário" [Tagebuch] já no ano de 1910, no $2^{\circ}$ caderno (D 82; 16.dez.1910). Essa incerteza, por sua vez, guarda estreita relação com outro aspecto desses diários: a sua natureza. É comum que se questione se seriam os registros neles contidos realmente de cunho personalíssimo ou teria Kafka a intenção de publicá-los. Algumas circunstâncias sustentariam essa dubiedade, dentre as quais não só o fato de Kafka ter entregado todos os cadernos in-quarto à Milena no início de out. $1921^{4}$ quanto o de o próprio diarista não ter destruído essas notas, deixando tal tarefa a cargo de Brod, o que causa certa desconfiança sobre a veracidade do desejo manifestado. De todo modo, é preciso compreender o contexto que circundou a prática do diarista e, para tanto, é útil tecer breve comentário sobre do gênero em si, ainda que isso exija uma certa digressão.

\footnotetext{
${ }^{4}$ À exceção, como já apontado anteriormente, das folhas em branco do $12^{\circ}$, nas quais ele deu continuidade à prática após a entrega. Kafka conheceu Milena no outono de 1919, quando ela entrou em contato com ele, com o objetivo de traduzir Der Heizer. (T2: 203 ss.)
} 


\section{2. $\bigcirc$ gênero diário e as implicações junto a Kafka}

Não é pretensão deste artigo apresentar nem a evolução histórica do (sub)gênero ${ }^{5}$ nem mesmo as particularidades que o permeiam, mas, de modo bastante resumido, pode-se afirmar que o surgimento do diário íntimo só foi possível a partir de uma concepção muito bem delineada de indivíduo, fenômeno perceptível tão somente na era moderna. Sem a ideia de um sujeito separado e individualizado, a manutenção de um espaço para registro de uma subjetividade teria ficado prejudicada, pois dependente intrinsecamente da crença desse "eu" separado e individual, o que é, no curso da história, indissociável do desenvolvimento da classe burguesa (DIDIER 1991: 60). Há certamente práticas e exercícios que podem ser compreendidos como precursores dessa escrita essencialmente de si: ainda no século IV, as confissões de Santo Agostinho renderam a ele o epíteto de fundador do gênero autobiográfico; as meditações de Marco Aurélio surgidas séculos antes são também usualmente apontadas como pioneiras no prenúncio da escrita de si. Não obstante esses primeiros indícios da manifestação de um “eu”, é apenas na era moderna que a escrita autobiográfica ganha contornos de modo a permitir uma narrativa de um "eu" propriamente individualizado. Para tanto colaboraram fortemente os ensaios de Michel de Montaigne (1533-1592) e, especialmente, as confissões de Jean-Jacques Rousseau (1712-1778), consideradas, não por acaso, a "certidão de nascimento da autobiografia" (DOSSE 2009: 68). É nesse contexto de progressiva introspecção e subjetivação narrativa que pôde então florescer a prática do diário, favorecida grandemente pelo cristianismo, pelo recrudescimento do capitalismo, pelas revoluções francesa e industrial e pelo consequente individualismo crescente do mundo ocidental (DIDIER 1991: 60).

Em meio a esse ganho introspetivo, é o inglês Samuel Pepys, no século XVII, a ser comumente apontado como o precursor da prática diarística em sua acepção moderna. Mantidos os seus diários por quase uma década, suas quase 3000 páginas guardam valor de documento histórico e revelam um caráter subjetivo com significativos traços de interioridade, além de uma natureza essencialmente privada, em uma época em que a

\footnotetext{
5 Usualmente, ao se falar de narrativas de si ou textos de caráter autobiográfico, considera-se a "autobiografia" o gênero do qual adviriam vários subgêneros como a autobiografia stricto sensu, as memórias, os testemunhos, as crônicas, os diários etc. Portanto, é mais apropriado tratar o diário como subgênero, evitando-se, todavia, qualquer conotação negativa ou mesmo de subalternidade que possa advir do prefixo "sub".
} 
RUSSO, S. - Os diários de Franz Kafka: uma introdução

prática ainda gozava de seu caráter essencialmente sigiloso. ${ }^{6}$ Prova disso é a intenção de Pepys de manter suas notas secretas e inacessíveis a olhares alheios: não apenas seu diário só foi descoberto um século depois da sua morte como nele o diarista recorreu a técnicas de criptografia que comprovam o receio de ter a sua intimidade devassada por um outro.

Não obstante o cenário favorável para a manifestação de um eu individualizado e separado a partir da era moderna e a prática do diarista inglês, foi só no século XIX que foi possível testemunhar o "impulso pela individualização" atingir o seu clímax com o aparecimento do "diário íntimo", (MüLLER 2003: 575) quando a ideia de um "euconsciente" tornou-se bastante manifesta e encontra-se refletida nas notas de uma "geração intimista": com as práticas de Stendhal, Benjamin Constant, Henri-Frédéric Amiel, E. T. A. Hoffmann, August von Platen e Franz Grillparzer, o caráter pessoal e privado ganhou maior fôlego, e uma nova forma de narrar a si mesmo foi revelada (BOERNER 1969: 48). A prática do diário popularizou-se enormemente na virada do XVIII para o XIX, tornando-se um costume, um hábito, e refletindo uma cultura em gestação na época. Essa mudança comportamental pode ser muito bem observada por um minucioso e interessante estudo realizado por Marc-Antoine Jullien na França, publicado pela primeira vez em 1808. Inspirado pela escola de Pitágoras e em práticas militares de disciplina e rigor, Jullien (1828) formulava, já na virada do século, uma técnica de emprego hábil do tempo e que visava conhecer a si mesmo em Essai sur l'emploi du temps [Ensaio sobre o emprego do tempo]. Neste ensaio, ele propunha especialmente aos jovens que exercitassem um rígido método de vigilância e regulamentação adequada da vida por meio da manutenção de cadernetas onde o indivíduo deveria registrar suas observações, suas ações, seus desejos etc., em suma, a proposta era estabelecer uma prática capaz de possibilitar a investigação pormenorizada da vida do indivíduo, avaliada quantitativa e qualitativamente, ideia que muito se assemelha à prática do diário íntimo.

Por consistir em exercício de introspecção, o atributo que melhor caracteriza o gênero diário e o distingue dos demais textos autobiográficos - ao menos até o início do

\footnotetext{
${ }^{6}$ Neste artigo, as concepções do gênero são aquelas atinentes à transição do século XIX para o XX, por ser essa a época por onde transitou o diarista objeto deste artigo. A esse respeito, ressalte-se que Didier (1991: 193) tem razão quando aponta o sério abalo da noção de indivíduo e do "eu" da nossa época, o qual tem implicações importantes na compreensão do que consiste a prática na atualidade, bastante distinta daquela empreendida no século XIX e na primeira metade do XX. Drasticamente diferente, não cabe aqui apontar os pormenores da conotação atribuída à prática nos dias de hoje, bastando mencionar o desuso cada vez mais acentuado do (sub)gênero, em que a internet, os blogs e as redes sociais mudaram radicalmente a sua proposta, em especial por trazer a presença ostensiva do outro, a quem é permitido interagir ininterrupta e constantemente com a "subjetividade" contemporânea.
}

Pandaemonium, São Paulo, v. 25, n. 45, jan.-abr. 2022, p. 187-211 
RUSSO, S. - Os diários de Franz Kafka: uma introdução

século XX - é, portanto, a sua destinação. Enquanto a escrita autobiográfica em geral pode ter como destinatário um outro - os testemunhos, as memórias e a autobiografia stricto sensu teriam usualmente como alvo um público leitor em geral; a carta, o seu remetente etc. -, o diário teve no seu proprietário, por décadas, o seu destinatário quase que exclusivo. É desse modo que uma aura secreta envolveu o (sub)gênero pelo menos até meados do século XIX, quando então a ideia de dar publicidade a esses textos de caráter intimista começou a ter algum lugar (LEJEUNE; BOGAERT 2003: 54). É desse modo que, no século XIX, se instala uma zona híbrida sobre os diaristas cujas práticas podiam ora ficar resguardadas pelo sigilo, ora sujeitas à publicidade, e é também por isso que Boerner, (1969: 51) um importante estudioso do (sub)gênero, vai afirmar que, já na segunda metade daquele século (XIX), qualquer pessoa que mantivesse um diário estava consciente da possibilidade de ter suas notas confessionais impressas, mesmo que apenas após a sua morte, o que, de certa forma, já atenuaria o caráter sigiloso da prática.

Um último aspecto útil a respeito da evolução do gênero que deve ser comentado é o fenômeno da "literarização" que adveio desse novo cenário, ou seja, diante da possibilidade de ter sua intimidade "devassada", o diarista podia antecipar-se e, assim, proceder a uma elaboração e ornamentação do texto. Observada a partir de meados do século XIX - mas especialmente do XX -, essa literarização fez com que alguns diários assumissem um caráter eminentemente literário (não necessariamente ficcional), deixando de ser exclusivo espaço de confidência e passando para o de elaboração textual, (DIDIER 1991: 46) o que colaborou para que diaristas optassem por manter a prática com propósito declarado de publicá-los em vida ou postumamente, de que são exemplos os diários de Max Frisch, Thomas Mann e Peter Handke.

Por ser o século XIX afetado por essa zona de transição, nem sempre fica claro, portanto, se determinada prática foi mantida com fins genuinamente privados ou se teria outros propósitos, e afirmar categoricamente com qual finalidade uma prática foi mantida não é tarefa simples, ficando sempre sujeita à arbitrariedade de quem avalia. É precisamente nessa conjectura que Kafka manteve o seu diário, não surpreendendo, assim, que haja dúvidas também quanto ao caráter secreto dos seus registros, sendo dois os motivos geralmente levantados para tal suspeita. Em primeiro lugar, a já mencionada entrega dos diários para um outro em out.1921 e, em segundo lugar, a natureza literária das entradas, reforçada pela presença de inúmeros fragmentos ficcionais - ponto que será abordado mais adiante. Esclarecer as nuances que envolvem esses fatores exigiria uma 
longa e pormenorizada discussão, mas, por enquanto, basta afirmar que essa entrega à Milena só ocorreu no último diário $\left(12^{\circ}\right)$ e não há indícios concretos de que o diarista objetivasse algo que não o compartilhamento de notas que já contavam com certo distanciamento seu - quando da entrega dos cadernos in-quarto, Kafka não fazia anotações há mais de 1 ano e meio. Quanto ao segundo aspecto, Kafka certamente não escapa ao fenômeno da literarização a que se submeteu a prática na virada do século, mesmo porque "ser escritor" foi o mote confesso da sua existência e que pode muito bem ser identificado nos papéis de natureza íntima, mas isso não significa que suas notas tivessem outro destinatário que não ele mesmo. Deve-se levar ainda em consideração que diários mantidos por escritores são naturalmente distintos daqueles mantidos por pessoas “comuns". É bastante natural encontrar nessas anotações de cunho intimista projetos de trabalhos futuros, esboços de textos, comentários sobre a atividade de escritor, o que pode levar a alguma confusão a respeito da prática desses diaristas-escritores, e isso porque esse hábito torna muito sutil a fronteira entre vida e arte. De todo modo, não há nenhum indício irrefutável que demonstre que Kafka tinha a intenção de dar publicidade a esses registros, fosse em vida ou mesmo após a sua morte. ${ }^{7}$

Superadas algumas desconfianças iniciais difundidas na crítica e retomando os doze cadernos in-quarto em seu conjunto, é possível - ainda que muito superficialmente - dividir os diários em fases, para fins "pedagógicos" e amparado principalmente pelo teor das anotações: (1) nota inaugural até mai.1910, quando do primeiro apontamento cronológico que fez do caderno formalmente um diário; (2) de mai.1910 até set.1912, quando se dá o efetivo "nascimento" de Kafka como escritor por meio da redação de das Urteil [O Veredicto]; (3) de set.1912 a set.1917, quando se observa uma inflexão nos registros derivada, em grande parte, do diagnóstico da tuberculose - que veio a ser uma das causas de sua morte sete anos mais tarde; (4) de set.1917 a out.1921, com a estagnação da prática e quando então os diários foram praticamente deixados de lado; e (5) de out.1921 a jun.1923, com a entrega dos cadernos in-quarto à Milena e a consequente retomada do último diário, no qual o diarista intensifica o caráter reflexivo e interiorizado das entradas que testemunham o agravamento da doença. Esses apontamentos

\footnotetext{
${ }^{7}$ Há aqueles que vão além ao afirmarem que os diários, independentemente se mantidos com fins de publicação ou não, seriam de natureza ficcional. Essa é uma discussão que certamente exigiria um novo artigo, não sendo este o local adequado para tanto, mas da leitura acurada desses diários é possível afirmar com alguma certeza que a caracterização dessas notas como ficcional não encontra nenhum respaldo (Cf. RUSSO 2020).
} 
RUSSO, S. - Os diários de Franz Kafka: uma introdução

introdutórios sobre a origem desses diários, algumas das suas particularidades e características mais significativas, assim como sobre a sua natureza, permitem que se aborde a recepção dessas notas junto ao público leitor para que, na sequência, sejam esses cadernos melhor examinados.

\section{A recepção dos doze cadernos in-quarto}

Mantidos até um ano antes da sua morte, o teor dos doze diários foi a público postumamente mais de uma década mais tarde. Foi Brod, o célebre amigo testamentário, o responsável por dar publicidade a esses cadernos, a quem cabia supostamente o oposto. Logo após a morte do amigo, Brod teria encontrado na escrivaninha de Kafka um bilhete destinado a ele, redigido muito provavelmente em 1921, no qual declarava o seu último pedido: a destruição de tudo o que havia escrito, sem exceção, incluindo a sua escrita de natureza íntima. Um segundo testamento redigido mais tarde (29.nov.1922) relativizava o pedido anterior, excepcionando alguns textos, mas mantinha no pedido - mesmo que não explicitamente - que se desse o devido fim aos diários e às cartas. ${ }^{8}$

Cabendo a Brod a gestão de todos os escritos deixados, ele optou por dar início à publicação do legado do amigo, e os diários íntimos foram levados a público, pela primeira vez, em 1937, no sexto volume da Gesammelte Schriften - antes dessa publicação "completa”, alguns trechos dos diários apareceram já na década de 1920, de modo esparso e não sistemático (BINDER 1979: 548). Esse foi, sem dúvida, um importante feito, em especial se se leva em consideração o contexto editorial da época. A década de 1930 foi marcada pelos recrudescimentos políticos do entreguerras, e o mercado editorial enfrentava, por razões óbvias, dificuldades. Sendo Kafka um autor não tão popular quando da sua morte - ainda que já reconhecido em vida pelo seu trabalho literário -, a publicação de seus diários não era nem viável nem rentável, e isso pela própria fragmentação intrínseca ao gênero. Ocorre que essa natureza fragmentada exigiu de Brod algumas ingerências no texto publicado e que integra a já conhecida problemática editorial que envolveu a sua atuação na publicação de toda a obra póstuma do amigo. Essas ingerências, por sua vez, afetaram certamente a recepção dos cadernos in-quarto.

\footnotetext{
${ }^{8}$ Cf. o texto integral dos dois "testamentos" em Stach 2017: 437 e 514. As versões originais em alemão dos dois testamentos podem ser também consultadas em http://www.franzkafka.de/franzkafka/fundstueck/457426.
} 
RUSSO, S. - Os diários de Franz Kafka: uma introdução

Como resultado dessas intervenções teve-se um texto significativamente reduzido, em que entradas inteiras - assim como nomes de pessoas - foram suprimidas, além de um texto integralmente reestruturado, cujos registros foram organizados cronologicamente, de modo a tornar o conteúdo dos cadernos mais coeso e atrativo ao público leitor. Um parêntese faz-se necessário: por sua natureza essencialmente fragmentada, a publicação de um gênero como o diário exigia, em geral, um razoável trabalho de intervenção, por meio de omissões, censuras, reestruturações etc., de modo a tornar o texto mais acabado, mais "legível", o que raramente era informado ao leitor. Essa é, antes de tudo, uma exigência editorial e foi um procedimento bastante útil especialmente na publicação de práticas diarísticas mais antigas, quando a crítica genética pouco tinha a contribuir ao interesse do leitor por um texto dito mais "puro". De certo modo, isso pode ser um ponto a favor do trabalho promovido por Brod, não obstante as perdas efetivas que isso causou na recepção desses diários.

Diferindo de maneira significativa do original portanto, o texto levado a público em 1937 acabou perpetuando o acesso precário a esses cadernos por décadas. Foi apenas nos anos 1990 que parte considerável dessas distorções puderam finalmente ser identificadas e "corrigidas", quando a edição crítica tornou disponível um texto muito mais fiel aos manuscritos. Paralelamente há um trabalho ainda mais minucioso que vem sendo realizado junto a esses manuscritos, mas que ainda é bastante parcial. Desde 2001, Roland Reuß e Peter Staengle organizam uma edição fac-símile histórico-crítica que tem, em relação à edição crítica, a especial vantagem de tornar disponível os fac-símiles das páginas dos manuscritos dos diários. Os $1^{\circ}$ e $2^{\circ}$ cadernos in-quarto ficaram disponíveis em 2001, o $3^{\circ}$ e o $4^{\circ}$ apenas duas décadas mais tarde, em 2020, não havendo previsão para os remanescentes. Além de só estarem disponíveis os cadernos 1 ao 4 , há ainda a desvantagem de a aquisição desses exemplares serem de elevado custo a quaisquer interessados.

Sendo essas iniciativas "reparadoras" bastante recentes, leitores, estudiosos e pesquisadores acessaram, por mais de meio século, edições desses diários substancialmente diferentes do original - o que também tem implicações importantes para toda a obra ficcional do autor -, podendo provocar equívocos de avaliação assim como prejudicar uma apreensão criteriosa da prática mantida por Kafka, o que fica particularmente evidente no caso das traduções desses cadernos para a língua portuguesa. 
RUSSO, S. - Os diários de Franz Kafka: uma introdução

\section{A tradução para a língua portuguesa}

Mesmo uma edição "precária” tal qual a disponível nos anos 1930 demoraria um tempo razoável até ser acessível ao leitor brasileiro. Sabe-se que o primeiro texto de Kafka a ser recepcionado no Brasil foi Erstes Leid, traduzido em uma revista semanal da época como Um artista do trapézio, em mar.1946. Os diários, por sua vez, foram aqui traduzidos apenas em 1964, em meio ao conhecido trabalho de tradução feito junto à Editora Livraria Exposição do Livro (mais tarde, Hemus) por Torrieri Guimarães, um dos maiores responsáveis pela disseminação dos textos do escritor no território nacional. Ocorre que não apenas Torrieri parte da edição incompleta e reformulada de Brod como sequer parte da língua original alemã, tendo sido feita de uma tradução espanhola - e não francesa como atestou Guimarães por anos (BotTMAnN 2014: 217 ss. e CRUZ 2007: 201). De todo modo, uma tradução para o português só ficou aqui disponível a partir de 1964, não havendo registro de que qualquer esforço para a tradução desses textos tenha sido feito antes disso, com exceção de pouquíssimos trechos e entradas desses diários que foram levados a público na Revista Joaquim, n. 14, em out.1947, no texto intitulado $O$ só em Kafka de Georges Wilhelm (BOTTMANN 2014: 229).

Nas décadas seguintes, houve outras tentativas para traduzir os diários, mas todas elas ainda mais precárias do que aquela feita por Torrieri em 1964: nos anos 1970, Osvaldo da Purificação assinou a tradução - agora de uma versão inglesa - juntamente com a Editora Nova Época de $O$ diário íntimo de Kafka, reduzindo ainda mais o texto, ao retirar todas as notas de viagem e selecionar menos da metade da tradução de Torrieri, além de suprimir os anos a que as entradas correspondiam; em 2000, a Editora Itatiaia trouxe novamente os Diários no $10^{\circ}$ volume da Coleção Obras de Franz Kafka, mais uma vez assinada por Guimarães, com um texto ainda mais reduzido em relação àquele traduzido nos anos 1960 - cerca de apenas 30\%. Nenhuma das ingerências editoriais é informada ao leitor, o que prejudica consideravelmente a recepção desses textos pelo público leitor também em nosso país. 
RUSSO, S. - Os diários de Franz Kafka: uma introdução

Figura 1 - Primeiras traduções dos diários de Kafka no Brasil

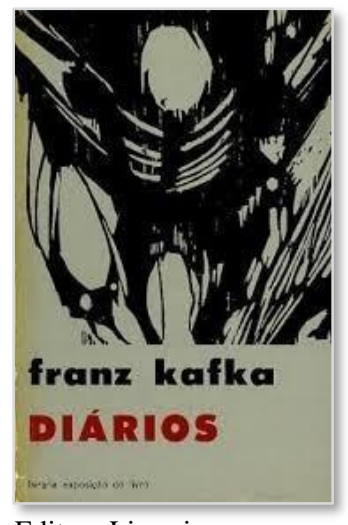

Editora Livraria

Exposição do Livro, 1964
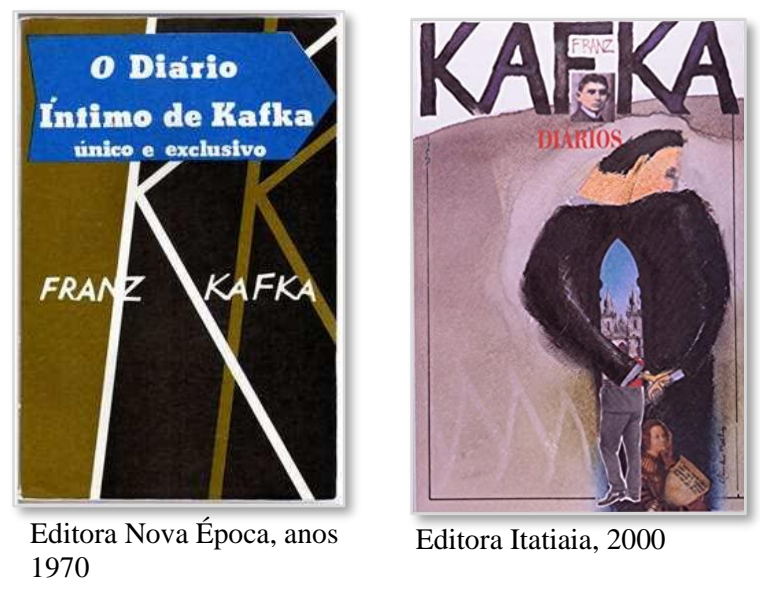

Editora Itatiaia, 2000

Fonte: Autoria Própria | Acervo particular

Não obstante essas tentativas, a primeira tradução de Torrieri (1964) permaneceu a edição mais popular e completa, tendo sido ela, por quase meio século, a mais "razoável". Esse quadro muda apenas muito recentemente, quando finalmente surgiu, em Portugal, uma tradução mais próxima do original, por meio do trabalho de Isabel de Castro Silva junto da editora Relógio D’Água, que fez a tradução de todos os cadernos in-quarto tendo como base a edição crítica disponível desde os anos 1990 - e, portanto, o texto original em alemão -, incluindo os diários de viagem. A recepção desses cadernos em Portugal não é muito diferente, demorando eles a despertar o real interesse de editoras e tradutores. A primeira tradução desses textos identificada foi a de Alfredo Margarido pela Guimarães Editores também na década 1960 (mais precisamente em 1961), sob o título Antologia de páginas íntimas. Tal como o próprio nome sugere, o exemplar traz a seleção de alguns trechos dos diários ao lado de outros textos de caráter íntimo do autor, sem uma precisa sistematização. Em 1986, Maria Adélia Silva Melo foi responsável por uma nova tradução junto da Editora Difel, tendo também como base a edição de Brod e trazendo apenas fragmentos dos diários.

No Brasil, os esforços para traduzir integralmente o texto dos diários é ainda vacilante e não parece realizável no curto prazo. Às investidas de Torrieri e Osvaldo da Purificação seguiu-se um longo período de silêncio em relação a eles, sendo muito recente a retomada dessas traduções. Em 2019, a L\&PM surpreendeu ao publicar os quatro primeiros anos dos diários - Diários 1909-1912 - com tradução de Renato Zwick, o primeiro tradutor brasileiro a usar o texto original em alemão dos cadernos in-quarto e a basear-se na edição crítica disponível já há três décadas, mas que tem a desvantagem de 
RUSSO, S. - Os diários de Franz Kafka: uma introdução

ser apenas parcial. ${ }^{9}$ Portanto, a quem interesse acessar a tradução integral dos diários o trabalho de Isabel de Castro Silva permanece sendo o mais confiável a leitores de língua portuguesa, apesar do inconveniente de se tratar de edição importada, o que dificulta o acesso à obra.

Figura 2 - Traduções recentes dos diários de Kafka para a língua portuguesa

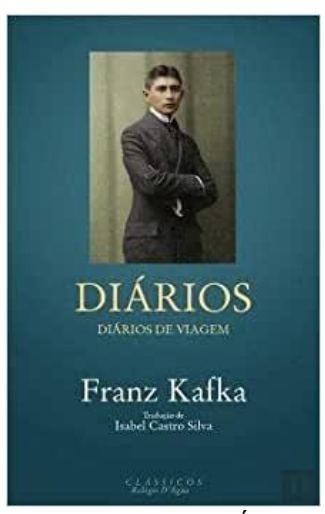

Editora Relógio D’Água, 2014 (Portugal)

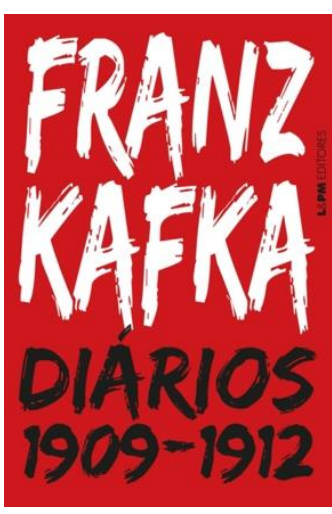

Editora L\&PM, 2019

Fonte: Autoria Própria | Acervo particular

Pesquisadores, estudiosos e mesmo potenciais tradutores têm ainda a possibilidade de recorrer aos manuscritos dos diários que se encontram desde 1961 na Bodleian Library, em Oxford, o que, porém, não ocorre sem dificuldades. Por razões evidentes, o acesso a eles passa por uma criteriosa avaliação da equipe responsável pela sua conservação, sendo todavia possível obter cópias digitalizadas de algumas páginas desses textos, ainda que haja a desvantagem da limitação no número de páginas e dos elevados custos. Há um projeto da Biblioteca de Oxford de tornar esses textos digitalmente acessíveis a todos, mas infelizmente não há previsão de quando isso se tornará realidade.

Não obstante a já mencionada natureza fragmentada do gênero, o diário sempre despertou - e desperta cada vez mais - interesse nos leitores, o que, de certa forma, contrasta com o relativo "atraso" na atenção dada a esses textos e que traz algumas consequências, dentre as quais certa negligência acadêmica no tratamento dessa parte fundamental do espólio do autor. Recepcionados no Brasil ainda na década de 1960, pode-se dizer que os caderno in-quarto foram relativamente relegados por bastante tempo

\footnotetext{
${ }^{9}$ Não há previsão para a publicação dos anos restantes (1913-1923). Ademais, em 3.jun.2017, o jornal $O$ estado de São Paulo noticiou que uma tradução com base na edição crítica estava sendo feita por Sérgio Tellaroli, pela Editora Todavia, mas não foi possível confirmar essa informação. Cf. https://cultura.estadao.com.br/blogs/direto-da-fonte/vontade-de-dancar/ (01/2019).
} 
RUSSO, S. - Os diários de Franz Kafka: uma introdução

entre leitores brasileiros e acadêmicos. Ainda que as citações de trechos seus sejam bastante comuns junto à crítica, poucos são os estudos dedicados exclusivamente a esses textos em sua integralidade, não sendo essa uma realidade exclusiva do nosso país. ${ }^{10}$ Restringindo apenas o Brasil, isso fica bastante evidente. O acervo da Biblioteca Digital Brasileira de Teses e Dissertações (BDTD), por exemplo, aponta que o primeiro trabalho sobre a obra do autor deu-se aqui no ano de 1974 e dos quase 100 trabalhos de pósgraduação stricto sensu dedicados a ele pouquíssimos são os que fazem menção aos diários, e nenhum tem neles seu corpus de investigação principal, servindo eles quase sempre e exclusivamente como mero material de apoio. Ter nesses cadernos o objeto exclusivo de investigação é particularmente interessante diante do fato de terem sido fonte para exegese da obra por décadas, ficando essas notas íntimas sujeitas a distorções, já que trechos e entradas são arbitrariamente retirados de seu contexto original.

Para além do modo como se deu a recepção e a tradução desses textos, há, claro, outros fatores que podem ter contribuído para essa negligência ter-se perpetuado por tanto tempo, dentre os quais as já datadas abordagens pós-estruturalistas e a propalada "morte do autor" de Roland Barthes, que causou certo constrangimento no mundo acadêmico em chamar o autor pelo primeiro nome e ter na sua vida íntima o eixo de investigação. Neste quesito, deve-se lembrar que não apenas a recepção da obra de Kafka foi muito anterior a essas abordagens e discussões como também o cenário atual é menos intimidador, e todos esses elementos - um cenário de "retorno" do autor e a disponibilidade de traduções mais fiáveis - contribuem para que leitores, estudiosos e pesquisadores resgatem esses diários. Esse resgate pode inclusive já ser verificado por meio de trabalhos de pós-

\footnotetext{
${ }^{10}$ Um levantamento de estudos dedicados primordialmente aos diários evidencia isso: em 1963, uma conferência proferida por Friedrich Beissner deu origem à Der Schacht von Babel: aus Kafkas Tagebüchern (Stuttgart: Kohlhammer); quase três décadas mais tarde, Manfred Hornschuh é o autor de Die Tagebücher Franz Kafkas: Funktionen, Formen, Kontraste (Frankfurt am Main: Lang, 1987); em 1991, surge o trabalho bastante robusto e coerente de Georg Guntermann, intitulado Vom Fremdwerden der Dinge beim Schreiben: Kafkas Tagebücher als literarische Physiognomie des Autors (Tübingen: Niemeyer), seguido pelo estudo de Anne Rother ("Vielleicht sind es Tenöre": Kafkas literarische Erfindungen in den frühen Tagebüchern. Bielefeld: Aisthesis, 1995); mais recentes são os trabalhos de Sophie von Glinski (Imaginationsprozesse. Verfahren phantastischen Erzählens in Kafkas Frühwerk. Berlin-New York: Gruyter: 2004), dedicado aos primeiros diários, e de Andrea Rother que, em "Hier muss ich mich festhalten..." Die Tagebücher von Franz Kafka: Ein literarisches Laboratorium. 1909-1923, (Berlin: 2007) tem o mérito de abranger os doze cadernos, proporcionando um panorama mais geral, cujo método de analisá-los sequencialmente (e não cronologicamente) visa demonstrar a evolução do trabalho e da escrita desse autor ao longo dos anos; a isso soma-se a perspectiva filosófica adotada por Elisabeth Lack em Kafkas bewegte Körper: die Tagebücher und Briefe als Laboratorien von Bewegung (München: Fink, 2009). Binder (1979: 550) menciona ainda a monografia (avaliada negativamente por ele) realizada por W. Giesekus sobre os diários íntimos e os de viagem, já três anos após a publicação da edição alemã desses textos.
} 
RUSSO, S. - Os diários de Franz Kafka: uma introdução

graduação realizados em nosso país que têm como objeto principal a escrita íntima do escrito tcheco, corrigindo finalmente a negligência constatada até pouco tempo em relação a esses cadernos. ${ }^{11}$

\section{Diários de Kafka: leitura, vida e obra}

“Porque lemos diários com tanto prazer?", pergunta Michael Maar (2013). Diários sempre despertaram interesse entre leitores, em especial aqueles mantidos por figuras que, de alguma forma, provocam admiração ou mesmo antipatia, e isso porque a sua leitura dá a impressão de que é possível acessar a personalidade - quase sempre enigmática - de seu proprietário. Esse interesse dos leitores tem indubitavelmente implicação no universo editorial, ainda que a publicação de um diário íntimo contrarie sua natureza originalmente secreta, sendo nesse contexto que diários são publicados e muito bem recepcionados pelo público pelo menos desde o século XX.

Ainda que Kafka não fosse um autor muito conhecido à época de sua morte, Brod identificou já nos anos 1930 algum potencial nesses textos, ao levá-los a público. Apesar desse potencial, a leitura dessas notas íntimas pode não ocorrer sem alguma frustração, e isso porque mesmo um gênero flexível como o diário não está isento de gerar expectativas em seus leitores (JURGENSEN 1979: 21 ss.). Quem acredite encontrar em seus doze cadernos in-quarto elementos suficientes para formatar uma imagem coesa e bem delineada do escritor tem grandes chances de ter sua leitura desapontada, o que não é, sem dúvida, uma prerrogativa exclusiva sua:

Eu achava que iria encontrar um autor e eu encontro um homem. Eis aqui a decepção; não é de modo algum um homem que eu queria encontrar: disso há o suficiente na rua e na cidade; era um autor, ou ainda melhor, um personagem que eu procurava. (DIDIER 1991: 175)

Um dos maiores diaristas em língua alemã do século XX é disso um exemplo emblemático: Thomas Mann, que aderiu à prática ao longo de praticamente toda a sua vida, frustrou seus leitores entusiasmados com seus volumosos registros pessoais ora pela sua banalidade, ora por revelarem uma natureza marcadamente narcisista (MAAR 2013). Isso decorre de vários fatores intrinsecamente relacionados ao próprio gênero, que incluem a sua natureza essencialmente fragmentada, a monotonia do cotidiano a ser

${ }^{11}$ Cf., por exemplo, GuATimosim, B. Kafka e a busca de sustentação: um corpo a se escrever. Tese (Doutorado em Letras) - Faculdade de Letras. Belo Horizonte, 2018. Cf. também Russo (2020).

Pandaemonium, São Paulo, v. 25, n. 45, jan.-abr. 2022, p. 187-211 
RUSSO, S. - Os diários de Franz Kafka: uma introdução

registrado, a introspecção filosófico-reflexiva e a flexibilidade de conteúdo, que sequer exige que o próprio diarista seja foco de textualização - esta é uma característica muito mais relacionada à autobiografia stricto sensu.

Da leitura das primeiras notas dos diários de Kafka, muito pouco sobre ele e a sua vida cotidiana é revelado, o que tanto pode colaborar para uma frustração na expectativa do leitor de acessar o caráter e a intimidade do diarista (THEISOHN 2010: 380 ss.) quanto para gerar dúvidas quanto ao real propósito de fazer tais registros. De fato, nem a sua vida nem a sua introspecção são nesse momento priorizados, e a primeira menção a algo diretamente relacionado a ele encontra-se na entrada em que a data foi apontada pela primeira vez (D 16). As notas que antecedem o apontamento temporal consistem em observações do mundo que o cerca, descrições literarizadas de objetos e situações, relatos de sonhos e, especialmente, na tematização daquilo que parece ter determinado toda a vida do diarista e que é refletido nos quatorze anos durantes os quais a prática foi mantida: a escrita, feita tema-protagonista de todos os doze diários. Essa devoção à coisa escrita leva inclusive alguns a afirmarem que esses diários não ofereceriam elementos biográficos e que, por essa razão, não deveriam ser lidos como textos puramente autobiográficos (ROTHER 2007: 10, BENNHOLDT-THOMSEN 2008: 21). Realmente, Kafka não tem nos elementos biográficos o foco de sua textualização, o que não significa dizer que esses doze cadernos não reflitam a sua mais íntima escrita de si mesmo, e isso porque é preciso compreender que foi na literatura e na escrita que ele encontrou a única forma de expressar a sua peculiar existência.

Desse modo, a leitura desses diários reflete a complexidade da maneira como Kafka via a si mesmo situado no mundo, e essa é certamente uma perspectiva fundamental a quem a sua obra interesse, em especial se se leva em consideração um apontamento bastante comum em relação ao escritor, qual seja a profunda simbiose entre vida e obra. A associação quase irrefletida entre a sua pessoa e o seu trabalho literário foi - e ainda é de modo menos explícito - a regra que determinou a sua recepção. Hipóteses dessa natureza certamente encontram fundamento nas declarações dele próprio, quando faz afirmações como: “O romance sou eu, minhas histórias sou eu"| "Der Roman bin ich, meine Geschichten sind ich" (BRF 223; 2./3.jan.1913) ou "Meu romance! [...] provavelmente eu não escrevo nada que seja completamente desconectado comigo" | "Mein Roman! [...] ich schreibe wohl nichts, was ganz außer Zusammenhang mit mir wäre”, (BRF 275; 26.jan.1913) ou quando ele narra a sua chegada em 1922 no Hotel 
RUSSO, S. - Os diários de Franz Kafka: uma introdução

Krone em Spindelmühle, local onde deu início a seu último romance, Das Schloss [O castelo]: ${ }^{12}$

Ainda que eu tenha escrito o meu nome com clareza ao hotel, ainda que eles já me tenham escrito duas vezes usando o meu nome corretamente, lá embaixo, na mesa, lê-se "Josef K.”. Deverei eu esclarecer a eles ou esperar que eles me esclareçam? (D 556; 27.jan.1922)

Trotzdem ich dem Hotel deutlich meinen Namen geschrieben habe, trotzdem auch sie mir zweimal schon richtig geschrieben haben, steht doch unten auf der Tafel Josef K. Soll ich sie aufklären oder soll ich mich von ihnen aufklären lassen? (T3: 893)

Essa simbiose não ocorre sem consequências para a prática de Kafka, cujas notas são caracterizadas por um profundo hibridismo: ao lado de apontamentos da vida cotidiana estão esboços literários, fragmento de cartas, desenhos, projetos e rotinas de escrita e mesmo textos ficcionais completos. A surpreendente presença de mais de 150 esboços ficcionais ao longo das entradas reflete esse imbricamento entre vida e literatura, o que leva a uma outra particularidade da prática mantida por ele: a dificuldade em se discernir quando se está diante de um texto ficcional ou de um vinculado à sua vida cotidiana. Ocasionalmente, é possível identificar a natureza do texto seja pela atribuição de um título provisório, seja por diálogos bem delineados, mas, em geral, o leitor dessas notas fica impossibilitado de fazer tal juízo com convicção, estando esses diários repletos de exemplos dessa natureza (Cf., por exemplo, D 70 ss.). Para melhor compreender a singularidade da prática mantida pelo diarista, é preciso então sondar os temas que permearam os registros feitos.

\section{Cadernos in-quarto: estrutura e conteúdo}

Muitos são os temas que transitam pelos cadernos in-quarto: descrições detalhadas de sonhos e gestualidades; inquirições sobre o corpo; rascunho de cartas; relatos sobre conferências e peças de teatros às quais o diarista assistiu; círculos de leituras; lembranças da infância e juventude; citações; reflexões sobre livros, escritores e outros diaristas, mas, dentre tantos assuntos, é - como já apontado - a escrita a assumir inquestionável protagonismo. Em meio a eventos biográficos e reflexões metafísicas, os registros são, em sua maioria, um tributo ao fazer literário e que, em seu conjunto, dão gradualmente forma a uma vida dedicada à literatura e ao ato de escrever, colaborando para a elaboração

\footnotetext{
${ }^{12}$ As traduções de trechos retirados de obras estrangeiras são minhas e as referentes a trechos citados dos diários de Kafka são de Isabel Castro Silva com eventuais modificações feitas por mim. Quando houver intervenção minha nas traduções desses diários, vocábulos e sentenças serão sublinhados.
}

Pandaemonium, São Paulo, v. 25, n. 45, jan.-abr. 2022, p. 187-211 
RUSSO, S. - Os diários de Franz Kafka: uma introdução

de uma biografia "artisticamente moldada" (BINDER 1976: 85).

Ainda que não seja a pretensão deste artigo esgotar a complexidade inerente à prática do escritor, é conveniente traçar um panorama de cada um dos diários, a fim de se obter uma ideia desses doze cadernos. Como apontado antes, o primeiro caderno inquarto foi aberto em 1909 e teve duração de dois anos (até out.1911). Da leitura dos primeiros registros feitos nele, o que mais surpreende é o a falta de apontamento temporal, o aspecto suspensivo das notas e, especialmente, a dificuldade de encontrar neles algo relacionado à realidade cotidiana do diarista. Neste primeiro diário, encontram-se principalmente relatos de experiência oníricas, descrições literarizadas de experiências vagas e, por vezes, impessoais, assim como incursões em textos marcadamente ficcionais. É em meio a essas investidas literárias em meados de 1910 que Kafka então deixou a caderneta temporariamente de lado com folhas ainda em branco e deu início ao segundo - o primeiro foi retomado meses mais tarde (fev.1911). O segundo caderno também foi iniciado sem demarcação cronológica, trazendo em sua entrada inaugural uma longa narrativa ficcional em $1^{\mathrm{a}}$ pessoa. Nele a data aparece apenas na $5^{\mathrm{a}}$ entrada - e não por acaso um de seus principais críticos considera este o início efetivo do diário (BINDER 1979: 540) -, e muitos são também aqui os excertos de natureza ficcional, sendo novamente a vida cotidiana do diarista pouco ou não explicitamente tematizada. A já aludida dificuldade em se discernir o que é ficção e o que se refere à pessoa do diarista fica especialmente evidente nesses dois primeiros cadernos, criando alguma dúvida em relação ao caráter genuinamente íntimo dessas notas. Isso é corroborado ainda mais pela maneira de proceder do diarista que opta, por vezes, por revisar, apagar, riscar e corrigir as entradas - marca de todos os cadernos -, imprimindo com isso alguma suspeita acerca de quem estaria escrevendo: se propriamente o diarista ou um (aspirante a) escritor (STACH 2015: 418 ss.).

O terceiro, o quarto e o quinto diários têm em comum a intensa dedicação do diarista à prática. $\mathrm{O}$ terceiro, por exemplo, foi aberto na sequência do anterior, e suas folhas preenchidas em menos de um mês (26.out.1911 a 24.nov.1911), onde anotou sobretudo reflexões sobre arte e suas experiências com o teatro e seus atores, chamando a atenção uma certa vivacidade social. No quarto caderno, a vida cotidiana torna-se cada vez mais textualizada e, paulatinamente, é possível esboçar um caráter - ainda que não ordinário - do diarista. Já no quinto, ele traz muito de suas leituras e autores preferidos, em especial seu interesse por textos autobiográficos, constando nele apenas uma narrativa 
RUSSO, S. - Os diários de Franz Kafka: uma introdução

literária, Der plötzliche Spaziergang [O passeio repentino]. Nele pode-se também observar, com certa nitidez, o movimento de reclusão que o diarista progressivamente promoveu, aspecto fundamental para compreender a constituição da sua identidade e, especialmente, a forma como ele via a si mesmo no mundo.

Dentre os doze diários é o sexto o que talvez se mostre o mais notável, por ser nele que o diarista logrou finalmente o seu efetivo nascimento como escritor, após a redação direta neste caderno do que ele considerou a sua primeira história [Geschichte] completa: das Urteil [O veredicto]. A essa história segue um período de intensa produtividade literária, testemunhado tanto pelo sexto diário quanto pelo subsequente. Entre este e aquele seguiu-se, porém, uma pausa de quatro meses, o que indica que durante este período Kafka dedicou-se intensamente à literatura fora dos diários. No sétimo, com início em fev. 1913, ele resgata a prática e nele registra eventos intimamente relacionados com o seu fazer literário, como a correção e a interpretação da sua novela Das Urteil e o esboço de Ernst-Liman, quando então também este caderno será deixado de lado por cerca de 1 ano, o que não significa o abandono da prática. Em seu lugar, tomou notas no oitavo, não sendo, todavia, os dois usados simultaneamente. Para além dos muitos esboços ficcionais, nesses dois cadernos $\left(7^{\circ}\right.$ e $\left.8^{\circ}\right)$, o diarista revela bastante da sua interioridade, de seus conflitos, de seus estados de ânimo etc., recorrendo, com frequência, à estratégia do autodiálogo, ao interpelar a si mesmo com o fim de compreender a sua situação e a sua existência (Cf., por exemplo, D 308; 9.mar.1914 e D 333; 6.ago.1914). Paulatinamente, fica evidente a crença do diarista em um único destino possível a ele: a literatura, para o que lhe foi exigido um movimento de reclusão social que fica refletido nas páginas desses diários.

Também sem datação, o nono traz em suas primeiras folhas experimentos literários que marcam todo o caderno, quando então o diarista acreditava ser a dedicação ao trabalho literário a única forma de mitigar seus conflitos. É neste período que têm origem os Konvolut I e II [papéis avulsos] que totalizam 9 folhas nas quais o diarista tomou notas entre agosto e novembro de 1914, quase todas voltadas para reflexões sobre literatura e seu trabalho como escritor. A partir do décimo diário, o caráter hipocondríaco e o alheamento social do diarista ficam ainda mais visíveis, com o que a introspecção ganha proporções cada vez maiores, atingindo o seu ápice no último caderno. Três meses separam o décimo do penúltimo, que será mantido por dois anos (set.1915 a ago.1917), mas a prática é mantida de modo bastante intermitente, chamando a atenção reflexões que 
RUSSO, S. - Os diários de Franz Kafka: uma introdução

fez a respeito da sua leitura da bíblia e ponderações sobre o seu judaísmo - tema bastante coadjuvante no conjunto dos registros. Até o décimo segundo caderno, pode-se dizer que a presença de esboços literários e a tematização da escrita são constantes.

Aberto na sequência do diagnóstico de tuberculose (ago.1917), o último diário foi o usado por mais tempo (1917 a 1923) e é o que apresenta o maior tom introspectivo. Ao longo dos seis anos pelos quais foi mantido, a dedicação aos registros varia consideravelmente, sendo abandonado por períodos relativamente longos. Um dos aspectos mais curiosos deste diário reside naquilo que ficou conhecido mais tarde como a série-Ele [Er-Reihe], que foi quando o diarista suprimiu a pessoa gramatical "eu" e passou a referir a si mesmo em terceira pessoa, "ele", procedimento esse que durou cerca de dois meses (6.jan.1920 a 29.fev.1920). É preciso lembrar que foi durante a manutenção desse caderno - ainda que após uma longa pausa de quase dois anos - que Kafka entregou todos os diários à Milena, os quais ele nunca mais voltaria a ver. Feita a entrega, ele então vai indagar a si mesmo: "Serei ainda capaz de manter uma espécie de diário? Em todo caso, será diferente". (D 546; 15.out.1921)| “Ob ich noch fähig bin eine Art Tagebuch zu führen? Es wird jedenfalls anders sein" (T3: 863). É provável que essa diferença a que Kafka aluda derive da possibilidade real de ter a sua interioridade devassada por um outro que não ele próprio, mas essa ruptura do caráter sigiloso do gênero não deve ser confundida com um desejo originário de destinar suas notas íntimas a um outro e isso pelos motivos que já foram antes apresentados. Mesmo após o gesto e a consequente desconfiança em relação à prática, o tom introspetivo e reflexivo foi mantido, e as notas sugerem que o avanço da doença o aproximou de assuntos espirituais. Outro aspecto notório é o fato de constar nele um único excerto ficcional, o que reflete a inflexão provocada pelo diagnóstico em 1917 na maneira de manifestar a sua subjetividade, agora muito mais voltada à possibilidade real de morrer. A última entrada data de 12.jun.1923 e, ainda que Dora Diamant (1995: 184), sua última companheira, alegue a existência de um diário mantido nos meses que antecederam a sua morte e que teria sido apreendido juntamente com as cartas - pela Gestapo, não há, como sugerido antes, indícios conclusivos acerca da existência de diários após esta entrada. Sobre o corpus desses diários, é ainda útil fazer um esclarecimento acerca do porquê outras escritas de natureza aparentemente íntima não foram integradas a eles. 
RUSSO, S. - Os diários de Franz Kafka: uma introdução

\section{Diários de viagem e cadernos in-oitavo}

Convencionou-se chamar de diários íntimos os doze cadernos in-quarto juntamente com o Konvolut. Há, todavia, muitas outras notas de caráter pessoal deixadas pelo escritor que não foram integradas à sua escrita diarística e que se encontram refletidas principalmente em dois outros lugares: os diários de viagem e os famosos cadernos in-oitavo - ambos também não publicados em vida. Ainda que ambos não sejam objetos deste artigo, vale a pena tecer breves comentários acerca de suas principais características, a fim de melhor distingui-los dos diários tidos como íntimos.

Os diários de viagem foram mantidos paralelamente aos $1^{\circ}, 6^{\circ}$ e $8^{\circ}$ cadernos inquarto e neles foram relatadas quatro viagens feitas entre jan.1911 a set.1913. A origem dessas anotações itinerárias está muito provavelmente relacionada à influência do amigo Brod, que insistiu para que ambos mantivessem registros das viagens que faziam juntos. Semelhantes aos cadernos in-quarto em sua forma e estrutura, distinguem-se particularmente pelo comprometimento com a factualidade e com os fenômenos externos àquele que toma as notas. Há certamente pontos de convergência, porém deve-se atentar para o fato de que essas anotações sempre tiveram como destinatário um outro, no caso, Brod, a quem os registros eram dados a ler, e também por isso não escaparam à elaboração textual e a uma ornamentação declaradas (BR 95; a Brod, 9.jul.1912). Não apenas o fato de terem sido feitos fora dos cadernos destinados à escrita essencialmente íntima imprime nesses registros uma natureza diversa, mas também a presença ostensiva desse outro.

Os cadernos in-oitavo, por sua vez, tiveram origem em uma fase mais tardia. Com o agravamento da sua saúde, Kafka recorreu não apenas aos cadernos in-quarto, mas também às oito famosas cadernetas azuis em formato oitavo [acht blauen Oktavhefte] doze sãos os cadernos neste formato, mas deste total, quatro foram usados apenas para estudos de hebraico (ROTHER 2007: 170). Mantidos por menos de 2 anos (nov.1916 a fev.1918), a principal diferença com os diários reside no material mais modesto e no tamanho significativamente menor (quase a metade), o que fazia deles mais fáceis de transportar e manusear: os cerca de $16 \times 10 \mathrm{~cm}$ dos cadernos in-oitavo contrastam com os $25 \times 20 \mathrm{~cm}$ dos caderno in-quarto. Com os doze diários, compartilham o seu tom e conteúdo: registros sobre o cotidiano, pensamentos suspensos, tom reflexivo das notas, rascunho de cartas e presença de esboços literários, nos quais também é difícil a diferenciação entre o que é ficcional e factual. Neles se encontram não apenas os seus

Pandaemonium, São Paulo, v. 25, n. 45, jan.-abr. 2022, p. 187-211 
RUSSO, S. - Os diários de Franz Kafka: uma introdução

célebres aforismos como também neles tiveram origem importantes narrativas curtas como Auf der Galerie, Die Brücke, Der Kübelreiter, Jäger Gracchus, Schakale und Araber, Das Schweigen der Sirenen, Prometheus, além de sua única incursão na dramaturgia, Der Gruftwächter. De todo modo, não devem ser confundidos com os diários. Para além do formato, é preciso ter em mente que outros elementos colaboram para que sejam as cadernetas in-oitavo tratadas como um conjunto de textos à parte, o que de fato foi feito tanto por Brod nos anos 1930 quanto pela edição crítica décadas mais tarde. Ademais foi o próprio Kafka a indicar que a natureza entre os ambos os cadernos - in-quarto e in-oitavo - era, de fato, distinta: três dos cadernos in-oitavo (E, F e G) ${ }^{13}$ foram usados concomitantemente com os $11^{\circ}$ e $12^{\circ}$ cadernos in-quarto, quando então registrou: "[...] eu ainda fluo em dois braços” (D 523; 10.nov.1917) "[...] ich fließe noch in zwei Armen", (T3: 843) fazendo muito provavelmente alusão a essa escrita paralela. Se fossem de natureza idêntica, os registros feitos à época não exigiriam dois distintos tipos de cadernos. Há uma evidência ainda mais notável de que Kafka não considerava os cadernos in-oitavo parte da sua prática diarística: quando da entrega de todos os diários à Milena em 1921, nenhuma das pequenas cadernetas azuis foi enviada a ela. Pelo o que foi exposto, é razoável que nem os diários de viagem nem os cadernos in-oitavo tenham sido integrados ao corpus dos diários íntimos.

Antes de encerrar esta apresentação dos diários de Kafka, é pertinente comentar um último aspecto: as funções que a prática cumpriu junto do diarista no decorrer de quatorze anos. Inúmeras são essas funções e não cabe aqui mencionar pormenorizadamente a que correspondiam elas, mas não se pode deixar de mencionar que ao atuar como meio epistemológico para compreender a sua existência, a escrita no - e fora do - diário funcionou indubitavelmente como instrumento para que Kafka cumprisse o que ele entendeu como o seu destino, ou seja, ser literatura, nada além de literatura, ${ }^{14}$ do que os doze cadernos são uma prova contundente. Da leitura de cada um

\footnotetext{
${ }^{13}$ Os cadernos in-oitavo foram editados em volume diverso daquele no qual Brod inclui os diários íntimos (Band VIII do Gesamtausgabe), optando, na época, por classificá-los com números ordinais de 1 a 8 . Os responsáveis pela edição crítica, por sua vez, decidiram igualmente por mantê-los fora do corpus dos diários, mas passaram a classificá-los com letras alfabéticas (A-H).

${ }^{14}$ Cf. a tão citada carta enviada à Felice Bauer: "Não tenho nenhum interesse em literatura, mas sou literatura; não sou nada além disso e não poderia ser outra coisa." | "Ich habe kein literarisches Interesse, sondern bestehe aus Literatur, ich bin nichts anders und kann nichts anderes sein." (BRF 479; 14.ago.1913)
} 
RUSSO, S. - Os diários de Franz Kafka: uma introdução

desses diários fica muito evidente que o diarista transformou a sua prática em uma arena na qual lutou pelo reconhecimento da sua subjetividade: foi precisamente neles que o diarista estipulou rotinas de escrita, realizou esboços, refletiu acerca de escolhas, encenou a si mesmo como escritor e desenvolveu a disciplina necessária para dar vazão ao monstruoso trabalho que esperava por ele, ${ }^{15}$ construindo assim para si uma identidade individual e singular.

Para tanto, ele recorreu a inúmeras leituras que o auxiliaram nessa constituição identitária. Não se deve negligenciar o fato de que foi um ávido leitor do gênero autobiográfico, interessando-se correntemente por diários íntimos, relatos de viagem e expedição, cartas, biografias, autobiografias e memórias. ${ }^{16}$ Por meio das leituras dos registros autobiográficos de suas figuras preferidas, dentre os quais destacam-se Grillparzer, Dostoiévski, Kleist, Flaubert e Goethe - a maioria deles vista como seus "parentes de sangue" [Blutsverwandte] (BRF 494; 2.set.1913) -, ele buscou modelos na construção da sua própria identidade e na orientação de como manter a sua prática como diarista, no que sem dúvida foi muito bem sucedido.

Quando se analisa detidamente a trajetória produtiva do escritor e a prática do diário, é notório que foram muitos os textos literários que se conhece hoje a terem origem direta nesses diários e, principalmente, que a quase absoluta maioria foi redigida após à manutenção da prática, ou seja, pós-1909, sendo, portanto, a gênese da obra de Kafka indubitável e intimamente ligada aos diários, em especial os seis primeiros, sem os quais muito provavelmente sua obra teria ficado impossibilitada. Em meio a sua papelada, Kafka deixou cerca de 40 textos em prosa (completos); 3400 páginas de diários e fragmentos literários, incluindo os seus 3 romances inacabados; os 2 testamentos para

\footnotetext{
15 "O trabalho em espera é monstruoso." (D 523; 10.nov.1917)| "Die wartende Arbeit ist ungeheuerlich." (T3: 843)

${ }^{16}$ Em meio a suas leituras, constam: os diários íntimos do filósofo e poeta Henri-Frédéric Amiel, Sören Kierkegaard e dos escritores Leo Tolstói e Friedrich Hebbel; os diários e as cartas dos poetas George Gordon Byron, Hebbel e Goethe; as cartas dos escritores Richard Dehmel, Dostoiévski, Flaubert, Theodor Fontane, Heinrich von Kleist e Nikolai Vasilievich Gogol e do pintor Vincent van Gogh; as biografias de Hebbel, dos escritores Christian Dietrich Grabbe, Goethe e Dostoiévski, dos filósofos Schopenhauer e Kierkegaard e do pintor Karl Stauffer-Bern; as autobiografias dos pintores Anselm Feuerbach e Albrecht Adam, dos escritores George Bernard Shaw, Fontane e Eduard Mörike e do filósofo Salomon Maimon; além das memórias do escritor Karl Immermann, da escritora Lulu Thürheim e do pintor Wilhelm von Kügelgen. Dentre suas leituras (auto)biográficas estavam, portanto, além de escritores, pintores, filósofos, políticos etc. Stach (2017: XII) vai dizer que todos - escritores ou não - tinham em comum uma atuação social que era capaz de retirá-los do anonimato. Vivendo aparentemente em mundos inconciliáveis, teriam compartilhado o fato de todos empregarem "estratégias e truques comparáveis para defender e expandir o domínio conquistado com dificuldade de sua existência". Por meio dessas leituras tão variadas, ele não apenas visava "obter ideias sobre a arte de viver", assim como tentava, por meio delas, descobrir como "criar para si um espaço no mundo".
}

Pandaemonium, São Paulo, v. 25, n. 45, jan.-abr. 2022, p. 187-211 
RUSSO, S. - Os diários de Franz Kafka: uma introdução

Brod; e cerca de 1500 cartas, que foram preservadas e publicadas (STACH 2017: IX ss.). Daquilo que se conhece hoje como seu trabalho literário muito pouco foi esboçado antes de 1909.

De tudo o que foi dito, conclui-se que, não obstante caiba ao leitor fazer o trabalho de elaborar o retrato deste singular escritor de que nos diários há apenas fragmentos dispersos, os doze cadernos in-quarto são imprescindíveis para compreender o legado deixado por ele. Como apontado, a prática mantida por mais de uma década possui particularidades, mas qualquer dúvida acerca da natureza desses registros deve ser suprimida e qualquer excepcionalidade que caracterize esses textos não significa uma não-correspondência ao gênero, antes o único diário possível de ser mantido por ele, para quem a vida e o fazer literário eram tão intimamente fundidos. Não por acaso, foi através da literatura, mais precisamente da escrita, que Kafka encontrou uma forma de (re)inserirse em um mundo do qual sentiu-se desde sempre afastado, e a leitura desses cadernos não deixa dúvidas a esse respeito.

\section{Referências bibliográficas}

Bennholdt-Thomsen, Anke. Schreiben statt Leben. Zu Kafkas Tagebüchern. In: HallerNevermann, Marie; ReHWINKel, Dieter (Org.) Franz Kafka - Visionär der Moderne. Göttingen: Wallstein Verlag, 2008, 15-36.

BINDER, Hartmut. Kafka in neuer Sicht. Mimik, Gestik und Personengefüge als Darstellungsformen des Autobiographischen. Stuttgart: J. B. Metzler, 1976.

BINDER, Hartmut. Tagebücher. In: BINDER, Hartmut (Org.). Kafka-Handbuch in zwei Bänden. Band 2: Das Werk und seine Wirkung. Stuttgart: Alfred Kröner Verlag, 1979, 539-554.

BOERNER, Peter. Tagebuch. Stuttgart: Metzler, 1969.

Bottmann, Denise. Kafka no Brasil: 1946-1979. TradTerm, v. 24, 213-238, 2014.

BROD, Max. Der Prager Kreis. Stuttgart: W. Kohlhammer Verlag, 1966.

BROD, Max. Nachwort. In: KAFKA, Franz. Tagebücher 1910-1923. Darmstadt: Moderner BuchClub, 1962.

CRUZ, Celso. Metamorfoses de Kafka. São Paulo: Annablume, 2007.

Diamant, Dora. Mein Leben mit Franz Kafka. In: KOCH, Hans-Gerd (Org.) "Als Kafka mir entgegenkam...” Erinnerungen an Franz Kafka. Berlin: K. Wagenbach, 1995.

DIDIER, Béatrice. Le journal intime. Paris: Presses Universitaires de France, 1991.

DosSE, François. O desafio biográfico: escrever uma vida. São Paulo: Edusp, 2009.

Guatimosim, B. Kafka e a busca de sustentação: um corpo a se escrever. Tese (Doutorado em Letras) - Faculdade de Letras. Belo Horizonte, 2018.

Jullien, Marc-Antoine. Essai sur l'emploi du temps. 4. ed. Paris: Dondey-Dupré, 1828.

JURGENSEN, Manfred. Das fiktionale Ich: Untersuchungen zum Tagebuch. Bern: A. Francke AG Verlag, 1979.

Pandaemonium, São Paulo, v. 25, n. 45, jan.-abr. 2022, p. 187-211 
RUSSO, S. - Os diários de Franz Kafka: uma introdução

KAFKA, Franz. Briefe. 1902-1924. In: BROD, Max (Org.). Gesammelte Werke. Frankfurt am Main: S. Fischer, 1958. [BR]

KAFKA, Franz. Briefe an Felice Bauer. Frankfurt am Main: S. Fischer Verlag, 2015. [BRF]

KAFKA, Franz. Diários. Tradução de Isabel Castro Silva. Lisboa: Relógio D’Água Editores, 2014. [D]

KAFKA, Franz. Tagebücher. Apparatband. Nach der kritischen Kafka-Ausgabe herausgegeben von Hans-Gerd Koch, Michael Müller und Malcolm Pasley. Frankfurt am Main: S. Fischer, 1990. [T1]

KAFKA, Franz. Tagebücher. Kommentarband. Nach der kritischen Kafka-Ausgabe herausgegeben von Hans-Gerd Koch, Michael Müller und Malcolm Pasley. Frankfurt am Main: S. Fischer, 1990. [T2]

KAFKA, Franz. Tagebücher. Textband. Nach der kritischen Kafka-Ausgabe herausgegeben von Hans-Gerd Koch, Michael Müller und Malcolm Pasley. Frankfurt am Main: S. Fischer, 1990. [T3]

LeJeune, Philippe; BogaerT, Catherine. Histoire d'un pratique, un journal à soi. Paris: Les Éditions Textuel, 2003.

MAAR, Michael. Heute bedeckt und kühl. Große Tagebücher von Samuel Pepys bis Virginia Woolf. München: C. H. Beck, 2013.

MÜLLER, Jan-Dirk (Org.). Reallexikon der deutschen Literaturwissenschaft: Neubearbeitung des Reallexikons der deutschen Literaturgeschichte. Band III (P-Z). Berlin: Walter de Gruyter, 2003, 574-577.

ROTHER, Andrea. "Hier muss ich mich festhalten..." Die Tagebücher von Franz Kafka: Ein literarisches Laboratorium 1909-1923. Tese (Doutorado em Literatura Alemã) Technische Universität Berlin, Berlin, 2007.

Russo, S. A escrita e os diários: a luta pelo reconhecimento da singularidade de Franz Kafka. Tese (Doutorado em Língua e Literatura Alemã) - Faculdade de Filosofia, Letras e Ciências Humanas, Universidade de São Paulo, São Paulo, 2020.

STACH, Reiner. Kafka. Die frühen Jahre (1883-1910). 4 Auf. Frankfurt am Main: S. Fischer Verlag, 2015.

STACH, Reiner. Kafka. Die Jahre der Entscheidungen (1910-1915). 7 Auf. Frankfurt am Main: S. Fischer Verlag, 2017.

TheIsoHn, Philipp. Kafkas Tagebücher. In: AuEROCHS, Bernd; EngEL, Manfred (Org.) KafkaHandbuch. Stuttgart: J.B. Metzler, 2010, 378-390. 